\title{
Recovery after cardiac arrest: the brain is the heart of the matter
}

\author{
J. Hofmeijer ${ }^{1,2} \cdot$ M. E. W. Hemels ${ }^{3,4}$
}

Published online: 6 September 2018

(c) The Author(s) 2018

Since the 1990s, survival rates of out-of-hospital cardiac arrest have increased considerably in the Netherlands, from $16 \%$ in 2006 to $23-27 \%$ in 2016 , to even $41 \%$ in patients with a shockable rhythm. In comparison, survival after cardiac arrest in the USA was $12 \%$ in 2016 [1,2]. The exemplary increase in survival in the Netherlands is related to national programmes aimed at increasing awareness of signs of cardiac arrest, providing education on basic life support to the general population, and making available dense networks of automated external defibrillators throughout the country [1, 2]. The Dutch Heart Foundation (Hartstichting) has formulated the criteria for so-called '6-minute zones' to save an additional 2,500 lives per year [3].

In sharp contrast with increased survival after cardiac arrest, neurological outcome has changed only marginally over the past decades. Of those surviving up to hospital admission, more than three-quarters initially remain comatose as a result of diffuse anoxic-ischaemic brain damage. Half of comatose patients die in hospital. Disturbances of motor function, cognition, mood, or other neurological impairments have been found in up to $100 \%$ of survivors $[4,5]$. Cognitive impairments are strongly related to reduced quality of life [6]. Rates of mortality, anxiety, and depression appear to be higher in women than in men [2, 4].

Early recognition of disturbances of motor function, cognition or mood would allow better guidance of patients, and open avenues for targeted treatments. Accordingly, both the Dutch and the European Resuscitation Council guidelines for cardiac rehabilitation recommend screening for cogni-

J. Hofmeijer

jhofmeijer@rijnstate.nl

1 Department of Neurology, Rijnstate Hospital, Arnhem, The Netherlands

2 Clinical Neurophysiology, Technical Medical Center, University of Twente, Enschede, The Netherlands

3 Department of Cardiology, Rijnstate Hospital, Arnhem, The Netherlands

4 Department of Cardiology, Radboud University Medical Center, Nijmegen, The Netherlands tive impairments and cognitive rehabilitation [7]. However, in patients that wake up from a coma, diagnosis and treatment are focused on cardiac function, while brain damage and neurological impairments are addressed infrequently and not systematically. Protocols to diagnose cognitive and subsequent functional impairments are scarce. There are no effective treatments to promote recovery of brain function and improve neurological outcome [8].

In this issue of the Netherlands Heart Journal, Boyce and co-workers assess the acceptance of the guideline recommendations amongst Dutch cardiologists and rehabilitation specialists, as well as their current implementation, by means of questionnaires [9]. The vast majority of responders acknowledged the importance of cognitive screening in cardiac arrest survivors, including the need for clear protocols. However, only a minority reported actual implementation of a cognitive screening protocol in their clinic. In addition, the authors analysed barriers to and success factors for implementation. They established the following barriers: lack of knowledge of cognitive disturbances amongst cardiologists, logistic and financial problems (that unfortunately were not further described), poor collaboration between cardiac and cognitive rehabilitation specialists, relatively small numbers of patients in some hospitals, and fear of administrative overload. Many respondents saw opportunities to implement protocols for the diagnosis and treatment of cognitive disturbances. These include more personalised treatment and a consequent decrease of dropouts during the cardiac rehabilitation programme.

We underscore the importance of brain damage after cardiac arrest and compliment Boyce and co-workers for their efforts to draw attention to this. It is our strong opinion that, after successful programmes to increase survival rates, we now have the responsibility to build on the growing evidence of cognitive and emotional impairments to improve neurological and psychiatric diagnosis and treatment. We will have to develop and implement a rational approach for the identification of brain damage, and to test rehabilitation treatments to promote functional recovery. Until further evidence becomes available, screening for cognitive impairments may be performed using the Montreal Cogni- 
tive Assessment, which takes a trained nurse just 10 min [9]. In the presence of relevant cognitive disturbances, cardiac rehabilitation may include psycho-education and strategy training. In this way, even a little effort may result in significant improvement of patient-oriented rehabilitation of survivors after cardiac arrest.

Open Access This article is distributed under the terms of the Creative Commons Attribution 4.0 International License (http:// creativecommons.org/licenses/by/4.0/), which permits unrestricted use, distribution, and reproduction in any medium, provided you give appropriate credit to the original author(s) and the source, provide a link to the Creative Commons license, and indicate if changes were made.

\section{References}

1. Husain S, Eisenberg M. Police AED programs: a systematic review and meta-analysis. Resuscitation. 2013;84:1184-91.
2. Hartstichting. Reanimatie in Nederland. Cijfers over overleving na hartstilstand buiten het ziekenhuis. 2016.

3. https://www.hartstichting.nl/reanimatie/6-minutenzone.

4. Green CR, Botha JA, Tiruvoipati R. Cognitive function, quality of life and mental health in survivors of out-of-hospital cardiac arrest: a review. Anaesth Intensive Care. 2015;43:568-76.

5. Moulaert VRMP, Verbunt JA, van Heugten CM, Wade DT. Cognitive impairments in survivors of out-of-hospital cardiac arrest: a systematic review. Resuscitation. 2009;80:297-305.

6. Moulaert VRMP, Wachelder EM, Verbunt JA, Wade DT, van Heugten CM. Determinants of quality of life in survivors of cardiac arrest. J Rehabil Med. 2010;42:553-8.

7. Nolan JP, Soar J, Cariou A, et al. European Resuscitation Council and European Society of Intensive Care Medicine 2015 guidelines for post-resuscitation care. Intensive Care Med. 2015;41:2039-56.

8. Nielsen N, Wetterslev J, Cronberg T, et al. Targeted temperature management at $33^{\circ} \mathrm{C}$ versus $36^{\circ} \mathrm{C}$ after cardiac arrest. $\mathrm{N}$ Engl $\mathrm{J}$ Med. 2013;369:2197-206.

9. Boyce LW, Goossens PH, Volker G, Exel HJ van, Vliet-Vlieland TPM, Bodegom-Vos L van. Attention needed for cognitive problems in patients after out of hospital cardiac arrest: an inventory about daily rehabilitation care. Neth Heart J. 2018. https://doi.org/ 10.1007/s12471-018-1151-z. 